\title{
CALL and the Saudi Arabian EFL Learners: An Action Research
}

\author{
Fahad Saleh Suleiman Alfallaj \\ College of Science and Arts, Methnab, Qassim University, Saudi Arabia \\ E-mail: Fh77d@hotmail.com
}

Doi:10.7575/aiac.alls.v.8n.2p.122

Received: 08/03/2017

URL: http://dx.doi.org/10.7575/aiac.alls.v.8n.2p.122

Accepted: 14/04/2017

\begin{abstract}
There is a growing consciousness to the need to know English among the Saudi Arabian peoples. This is apparent in the painstaking efforts of the policy makers in bringing in technology as an aid to teachers, institutions diverting huge funding to the field and encouraging research in the area. Learning outcomes, however, do not reflect these efforts. This study is an effort to zero in on factors that are impeding the expected proficiency of the Saudi EFL learner with special reference to the use of CALL. Having done this, the study makes pertinent recommendations with the larger aim of bringing the EFL learners to level playing ground in the global language scene. It is an Action Research carried out in the course of the researcher's teaching tenure at Qassim University in KSA.
\end{abstract}

Keywords: CALL, Action Research, Technology, Proficiency

\section{Introduction}

Classroom centred research (CCR) focused on the processes of teaching and learning in the EFL environment can provide invaluable insights into the product obtained. The methodology is quite simple actually: the teachers/researchers use a first-hand approach to data collection. They investigate the research question in the course of their class itself with the learners as the subjects. Contrary to other research methods, CCR is research that concentrates on the inputs to the classroom, or the outputs from the classroom. It is that type of research which is carried out by teachers to improve what goes on in their language classroom in an on-going cycle. This type of research is badly needed in language settings for the fact that teachers are combining theory with practice immediately in their classrooms. However, the onus to allow teachers sufficient time and ability to carry out problem focused or action research lies with the institution of employment. Academicians will agree that research is the key/solution to many problems that take place in the ESL classroom, especially when the research is carried by the teacher as Nunan (1989) has suggested. Language research that does not benefit the teacher and learners but benefits the academic researchers, is rather redundant (Beasly and Riodan, 1981). For teachers, this creates a gap between theory and practice. CCR on the other hand, tries to examine what happens inside the classroom when learners and teachers come together: CCR is in fact research that treats the language classroom not just as the setting for investigation but, more importantly, as the object of investigation. Classroom processes become the -central focus (Allwright, 1983).

The researcher of the current study has been engaged in Computer Assisted Language Learning (CALL) at Qassim University. This provided him with a rare opportunity to study the practical problems encountered in the use of CALL (this was until now only a conjecture among the teachers) and inspired him to undertake this Action or Classroom Centred Research in the benefit of the policy makers, University and, not to forget the centre of the teachers' universe, the learners.

\subsection{Previous Literature on Language Research Traditions}

Chaudron (1988) mentions that there are four traditions in ESL classroom research. These are: 1) Psychometric Studies: 2) Interaction Analysis; 3) Discourse Analysis; And 4) Ethnographic Analysis.

What is crucial about these research methodologies is that each one has its own purpose of investigation. Thus, each one has different focus and function. Therefore, we need to discuss them individually.

\section{Psychometric Studies}

Through this, the teacher/researcher investigates the effectiveness of methods, activities, etc. by measuring the language gain on proficiency test (Nunan, 1989). In this approach, the researcher will use statistical tools for the study. In short, the psychometric mirrors the quantitative research.

\section{Interaction Analysis approach}

In this approach, the research focuses on the social and behavioral interactions in the classroom (Chaudron, 1988). As a researcher, I agree with writers who look to the interaction analysis as a technique rather than a research tradition. The main reason is that the social and behavioural interactions could be investigated through the ethnographic analysis. 
Unlike the interaction analysis, the researcher here focuses on the interaction of linguistic aspects. Again, discourse analysis is more a research technique rather than a research tradition for the fact that the linguistic interactions could be investigated through the psychometric analysis.

\section{Ethnographic Analysis}

Duff (1995) states that "ethnography is just one of a variety of qualitative methods used to study educational issues" (p.507). In this approach, the researcher's study offers interpretive analyses of the events occurring in the classroom. Gegeo (1988) states that the ethnographic approach uses different methods like observation (and its different types), formal and informal interviews, documents and materials that are available or relevant. As I labeled the psychometric as quantitative, I will label the ethnography as qualitative.

Nunan (1989) quotes eight stages in the Action Research proposed by Cohen and Manion (1985). These are:

1. Identify the problem;

2. Develop a draft proposal based in discussion and negotiation between interested parties, i.e. Administrators, advisors, researchers, and sponsors, etc.;

3. Review what has been already been written about the issue in question;

4. Restate the problem or formulate hypotheses;

5. Select research procedures, resources, materials, methods, etc;

6. Choose evaluation procedures;

7. Collect the data, analyse it and provide feedback;

8. Interpret the data, draw out inferences and evaluate the project" (p. 12).

Kemmis and McTaggart (1985) mention four phases for Action Research. What is crucial about these phases is that they form part of an going cycle. These self-explanatory phases are:

1. Developing an action plan for improving what is happening;

2. Acting for implementing that plan;

3. Observing the effects of action in its context;

4. Reflecting on these effects.

\section{Review of Literature on the Use of CALL; its Strengths and Weaknesses in the language classroom}

In a study in 2017, Gu, Wang and Mason explored the relationship between cultural factors and emerging roles in computer assisted collaborative learning. The correlation so found was positive.

Ho, Sheng, Pei, Cheng-Ming (2017) developed a Ubiquitous Learning Instruction System With Augment Reality features to enhance the performance of EFL learning with authentic situations. Moreover, they explored the role of different learning strategies and cognitive styles in using UL-LAR to learn EFL.

Morch, Engeness, Cheng, Cheung, and Wong (2017) studied EssayCritic which is a computer based writing aid for EFL. They compared two feedback conditions: Automated feedback from EssayCritic (target class) and feedback from collaborating peers. The results showed that grades of students from both the classes improved, but in different ways. The students in the target class improved on content in their essays, while those in the comparison class improved in organisation of ideas.

In significant finding, Kuo, Brian, and Yu-Tung (2017) found among other things that subjects perceived learning through blogging as enhanced due to a sense of community and perceived collaborative learning, most students had positive attitudes towards the use of blogs and group learning experiences involving collaborative processes, and that individual dispositions had a potential influence on collaboration.

In a study spanning more than sixteen months, Heift and Rimrott (2012) investigated task-related variation in the performance of learners in a CALL programme. The study revealed that grammatical accuracy with respect to German word order was significantly higher with free composition for both the beginner and intermediate levels. Moreover, proficiency level also had a significant effect on L2 word order accuracy: Beginner students performed significantly better than intermediate learners on translation and sentence building.

Chapelle (2009) draws a relationship between SLA and CALL by touching upon multiple theoretical perspectives viz., Cognitive Linguistic, Psycholinguistic, Human Learning and Language in Social context. Clearly, introduction of CALL needs to consider these perspectives and evaluate their role in any SLA situation.

Garrett (2009) explores the modern uses of technology to facilitate the teaching and assessment of second languages and discusses the relationship between pedagogy, theory, technology, infrastructure, efficacy, copyright concerns, categories of software and evaluation. 
In the midst of a plethora of definitions for CALL, Levy's (1997:1) definition of CALL states clearly and broadly as "the search for and study of applications of the computer in language teaching and learning". Their one biggest strength is the immediate response provided to the learner for his/her input. This role was fulfilled to some extent by the Language Lab, a rage with the language teachers till a few decades ago. With the onset of the computer age and ICT (Information and Computer Technology), however, CALL caught the imagination of the teacher-learner combine. It has its strength and limitations. Let us look at some of the pros first.

1. CALL is an adaptable option as it can adjust to the learners' needs and abilities.

2. Traditional Language Classrooms cannot adapt to varied cognitive and learning styles of the learners which CALL can.

3. Learning pace can be modified using CALL: again, a factor that runs in favour of the learners.

4. With CALL, learners can avail of an individualised learning experience.

5. Contrary to the traditional classroom, a CALL programme gives class control to the learners in terms of process and progress.

6. Being 'with the times', it can act as a positive factor for learners' Motivation in language learning.

7. Animation, graphics etc may create more interest in the learners using CALL.

8. Being close to authentic communication, it lands learners in a better stead to use the language outside the classroom.

9. Immediate feedback and maintenance of progress record are additional benefits in CALL.

10. Finally, CALL is not subjective and hence, is non-critical and impartial to the learners.

\subsection{Limitations}

1. Human touch and presence is reduced to a minimum with introduction of CALL.

2. Teachers' role is reduced to that of a facilitator at best in a CALL enabled programme.

3. ELT professionals may have their preconceived biases against CALL as they may see it as a potential rival out to get their jobs.

4. Point 3 may cause uncalled for anxiety and negative attitudes among the language teachers.

5. Many teachers are not adept at ICT skills and may fear being put on professional fringes with the introduction of CALL.

6. Last but not the least, with greater intervention and dependence on computers, young learners may tend to be socially isolated.

As a teacher of CALL and as a researcher I can claim to be a witness to both the strengths and weaknesses of CALL. For sure, the programme has failed to bring about the sea change in learners' proficiency to the expected level.

\subsection{Research Objectives}

The current study aims to evaluate the efficacy of the CALL programme as a tool for the EFL class at Qassim University as opposed to conventional teaching-learning.

\subsection{Research Problem}

The researcher observed during his teaching tenure that even with the introduction of CALL for EFL at Qassim University, learning outcomes were much below the expected standards. Each year, a large amount of University funding is being diverted to introduction of modern pedagogical tools to the learning environment, especially EFL, due to the management's awareness of the very significant place that English has in these times. However, learner proficiency leaves a lot to be desired. This makes it imperative to look for the loopholes in the system and plug them.

\section{Methodology}

Since this study was conceptualised as an Action Research, the researcher divided the lecture hours equally between CALL and Conventional teaching, additionally ensuring that the prescribed syllabus was also divided into two halves, each being taught by one of the two pedagogies. The entire exercise spanned a period of four months in the researcher's Department and a Counterpart Department; the learners at both ends were not informed of the experiment.

At the end of the stipulated semester, we randomly distributed a simple ten-item questionnaire to sixty learners running the CALL programme. They were requested to answer the questions on-the-spot. Once the response sheets were collected, we chose a set of forty subjects that had the most in common. Of these forty, gender wise the subjects were equal in number with twenty each being males and females. They fell in the common age group of 20 to 25 years with similar socio-economic backgrounds.

The subjects were required to answer each item in the questionnaire on a Likert scale, a five point psychometric scale widely used to measure people's attitudes in socio-psychological research. It measures the extent of agreement or disagreement of the subject with a statement. In a Likert Scale, it is important that all the items in the questionnaire be closely related as the aim is ultimately to arrive at a conclusion about the acceptability or not of a certain input, CALL, in the current study. Each item may be answered with response options 1 through 5 where 1 stands for 'strongly agree' and 5 stands for 'strongly disagree'. Once the data was collected, we represented the sum total of all responses ( $\mathrm{N}=40)$ to an item on a Pie Diagram to demonstrate the results at a glance. The findings are summed up in the following section. 


\section{Findings and Interpretation of data leading to Conclusions:}

Table 1 below represents numerically the responses obtained to each item in the questionnaire.

Table 1. Questionnaire

\begin{tabular}{|c|c|c|c|c|c|c|c|}
\hline No. & Question & 1 & 2 & 3 & 4 & 5 & $\begin{array}{l}\text { Total } \\
\text { responses }\end{array}$ \\
\hline 1. & $\begin{array}{l}\text { With CALL I can learn more as I learn at my } \\
\text { own pace. }\end{array}$ & 1 & 1 & 2 & 19 & 17 & 40 \\
\hline 2. & $\begin{array}{l}\text { I feel motivated to go to my EFL class because } \\
\text { of CALL }\end{array}$ & 0 & 0 & 3 & 4 & 33 & 40 \\
\hline 3. & $\begin{array}{l}\text { Throughout the EFL class, I find myself } \\
\text { engaged in the lesson if CALL is being used. }\end{array}$ & 0 & 0 & 0 & 28 & 12 & 40 \\
\hline 4. & $\begin{array}{l}\text { I like my CALL class as I get greater } \\
\text { opportunity to collaborate with my peers. }\end{array}$ & 34 & 2 & 1 & 3 & 0 & 40 \\
\hline 5. & $\begin{array}{l}\text { My teacher in CALL is sufficiently tech savvy } \\
\text { to make the lesson interesting. }\end{array}$ & 0 & 15 & 11 & 7 & 7 & 40 \\
\hline 6. & $\begin{array}{l}\text { I feel I am learning more through CALL than I } \\
\text { did through the traditional EFL class. }\end{array}$ & 0 & 0 & 0 & 11 & 29 & 40 \\
\hline 7. & $\begin{array}{l}\text { I miss the teacher's instructional support in my } \\
\text { CALL classes. }\end{array}$ & 0 & 0 & 0 & 3 & 37 & 40 \\
\hline 8. & $\begin{array}{l}\text { My English Grammar skills improve the most } \\
\text { when we brainstorm to answer simple } \\
\text { exercises in the class. }\end{array}$ & 18 & 14 & 0 & 6 & 2 & 40 \\
\hline 9. & $\begin{array}{l}\text { Use of Multimedia improves my language } \\
\text { experience when the teacher uses it for the } \\
\text { Literature sections. }\end{array}$ & 27 & 9 & 4 & 0 & 0 & 40 \\
\hline 10. & $\begin{array}{l}\text { The interactive exercises for Listening- } \\
\text { Speaking give me real life language use } \\
\text { opportunities. }\end{array}$ & 4 & 5 & 0 & 11 & 20 & 40 \\
\hline
\end{tabular}

\subsection{Results At A Glance}

\section{Graphic Representation ofTotal Responses}

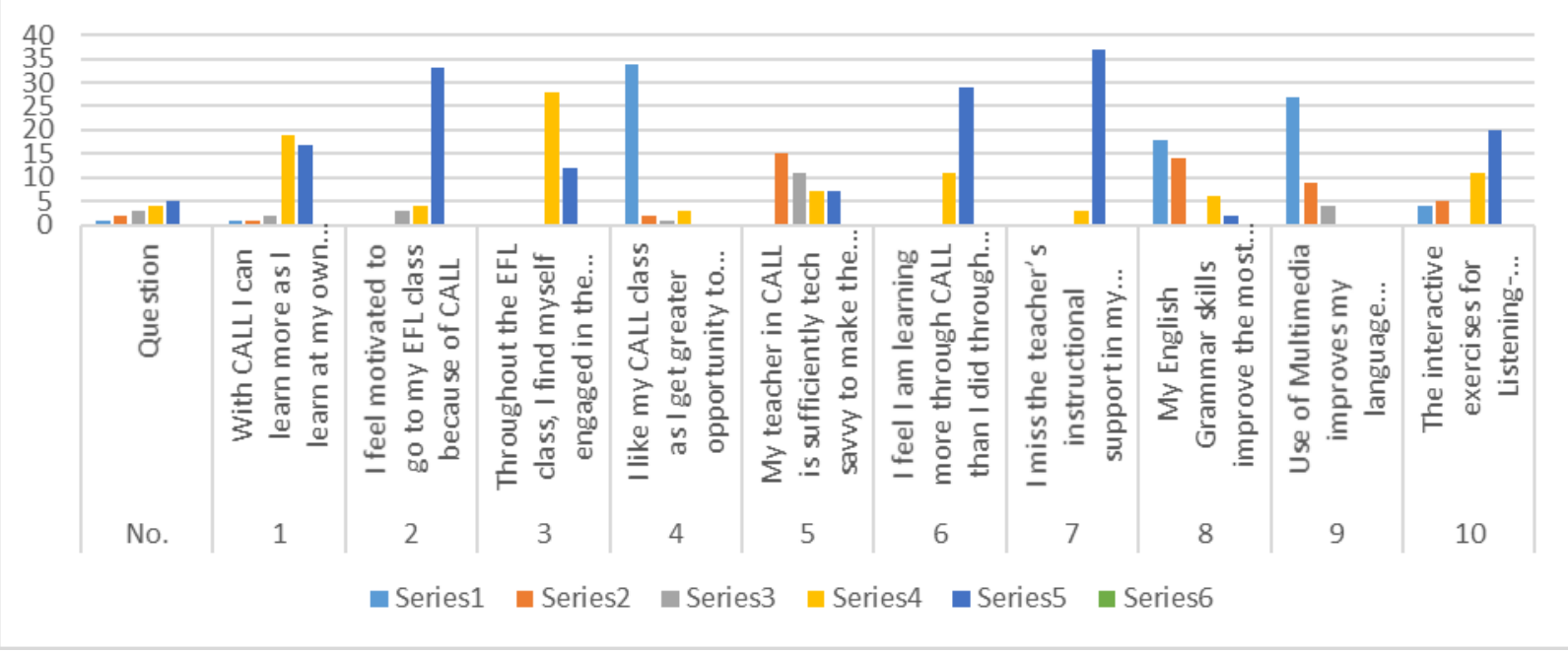

\subsection{Analysing the Questionnaire Item-wise}

Class observation of the subjects spread over a period of six months amply corroborates response to item 1 of the questionnaire. Ninety percent $(\mathrm{N}=36)$ of the respondents do not agree with the statement. These learners will be graded among the 'not proficient' EFL learners based upon their previous exam scores. It was observed that during the CALL sessions, a majority would lose interest in the activity within a few minutes of its commencement as their pace and proficiency were extremely poor leading to serious concerns about syllabus completion. The responses are depicted graphically below. 
1. With CALL I can learn more as I learn at my own pace.

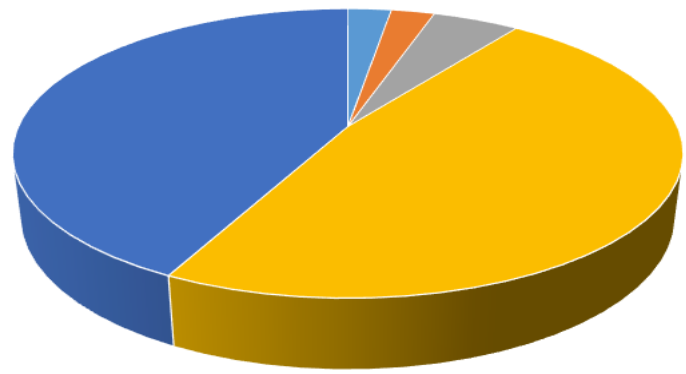

$=1=2=3=4 \cdot 5$

In response to item 2 of the Questionnaire, 92.5\% ( $=37)$ of the respondents reported in the negative to being motivated to attend the CALL class. We know that motivation plays a major role in SLA. The researcher also observed that every time a CALL class was scheduled, learners would find excuses to absent themselves but attendance was almost cent percent during traditional lectures. Graphically,

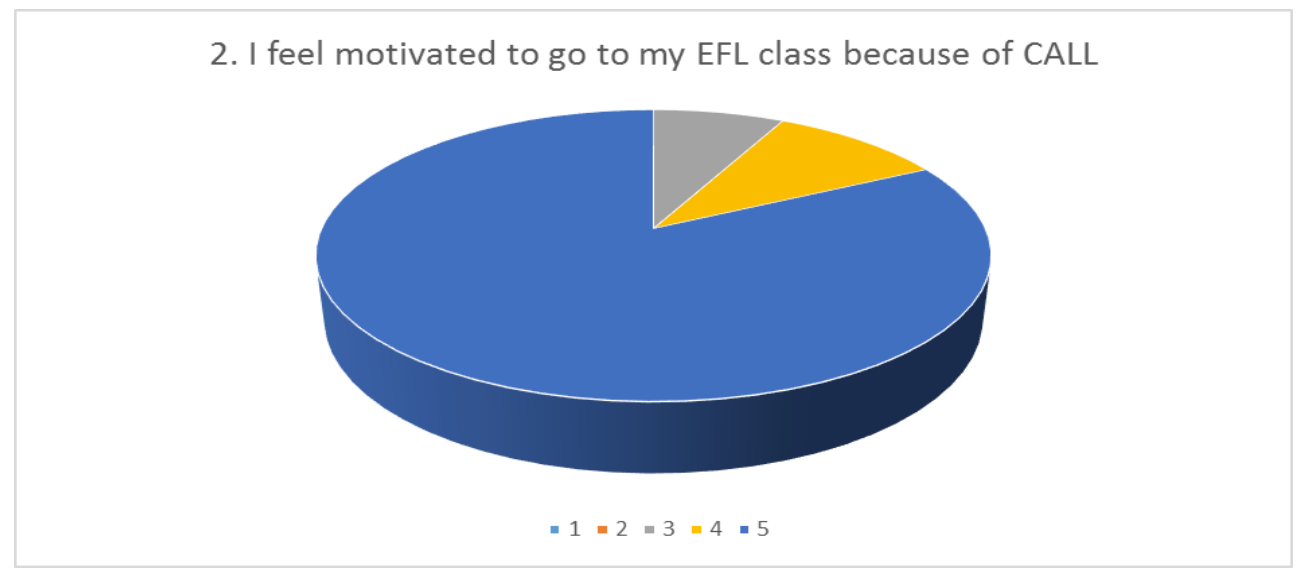

Above average (taken to be 3 on Likert Scale) responses $(\mathrm{N}=40)$ reported poor engagement in the class when CALL is being used. This is depicted graphically here:

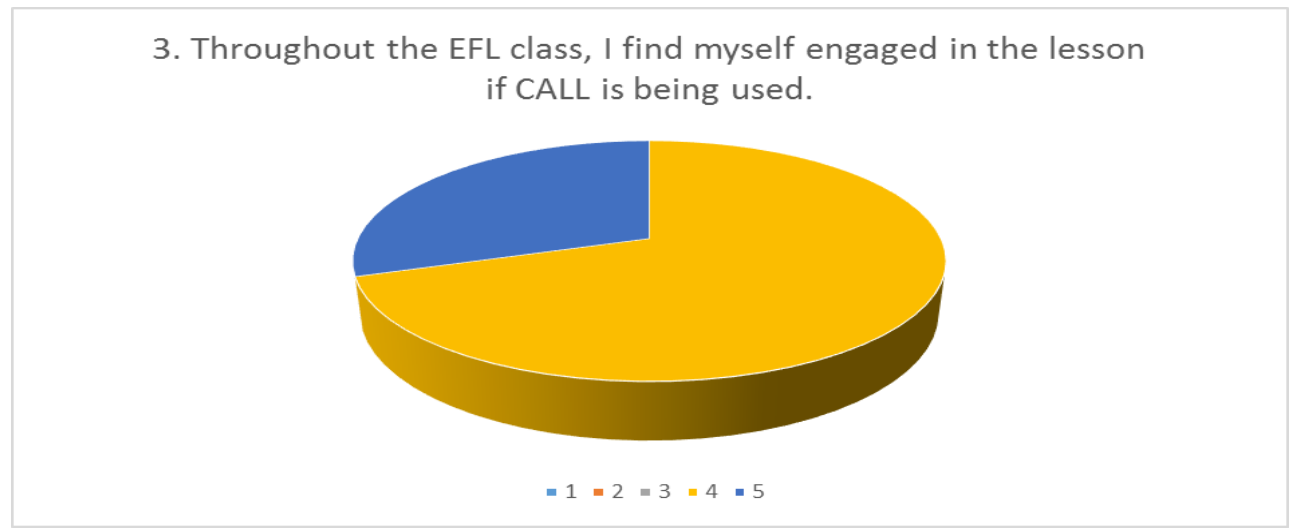

Responses to item 4 on the Questionnaire were interesting: Contrary to what the researcher observed, 90\% (N=36) of the respondents considered CALL to be desirable as it offered them the opportunity to 'collaborate' with the peers. In actuality, what is perceived by them as 'collaboration' was more of an opportunity to talk to the peers rather than collaborate on the task at hand. This response may, hence, be considered an aberration. 
4. I like my CALL class as I get greater opportunity to collaborate with my peers.

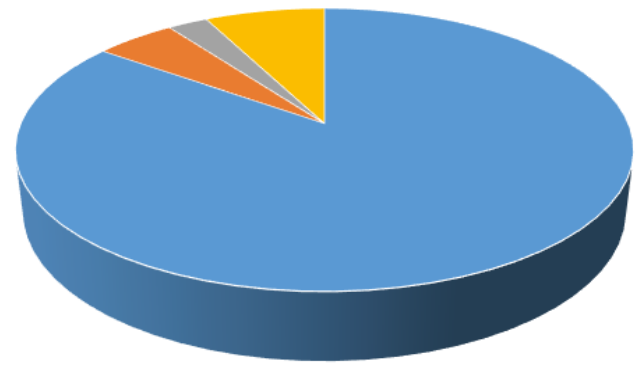

$=1 \cdot 2 \cdot 3=4 \cdot 5$

Sixty five ( $N=26$ ) percent of the respondents graded the CALL teacher as being sufficiently tech savvy to run the CALL class.

5. My teacher in CALL is sufficiently tech savvy to make the lesson interesting.

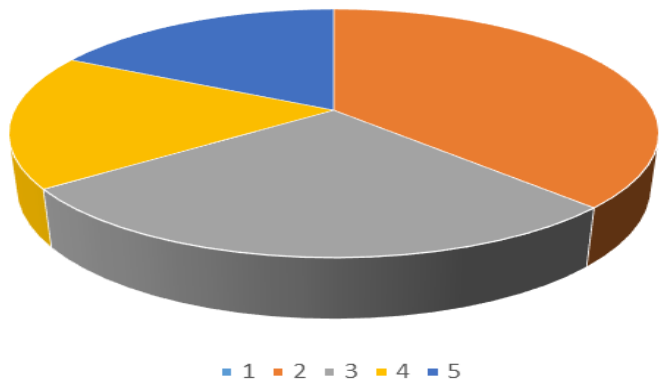

To item 6 of the Questionnaire, a majority of $72.5 \%(\mathrm{~N}=29)$ disagree when asked if they were learning more through CALL than the conventional class. The researcher observed during the CALL sessions that learners were rather engaged in learning and relearning the concepts for a very basic reason: They did not know how to seek clarifications for their doubts, a problem which was dealt with very promptly during conventional teaching sessions. Werepresent this graphically:

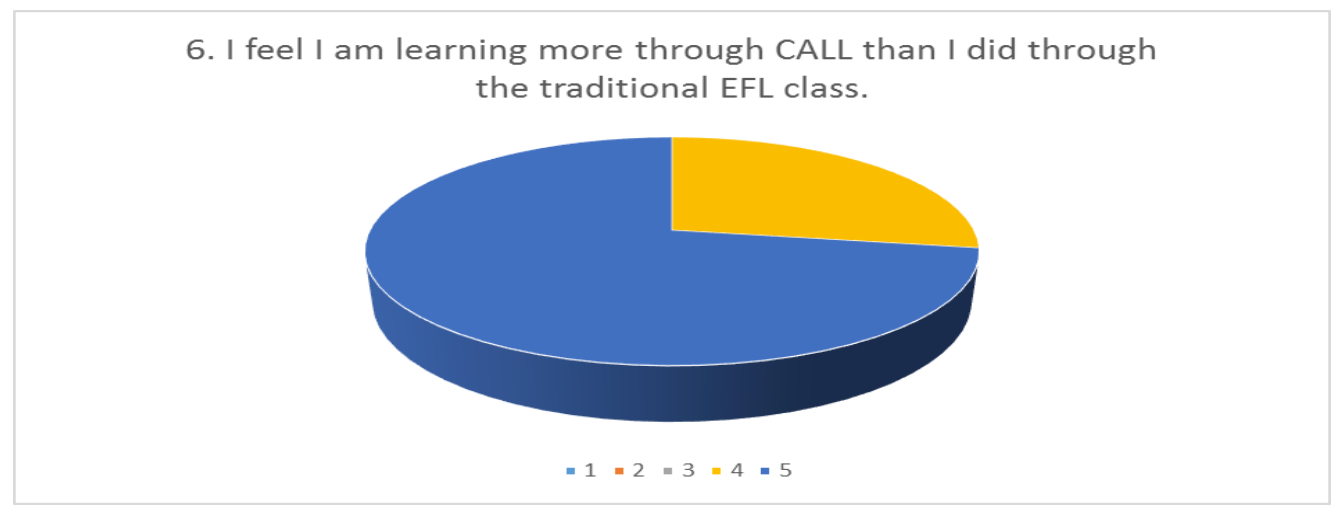

The earlier finding is corroborated by responses to the next item on the Questionnaire where as many as 92.5\% ( $\mathrm{N}=37$ ) report missing the instructional support of the teacher during the CALL sessions. It was seen by the researcher that during the CALL sessions, many respondents would seek the help of their peers for clearing the doubts, leading to obstruction in the peers' session and also general confusion in the class. 
7. I miss the teacher's instructional support in my CALL

classes.

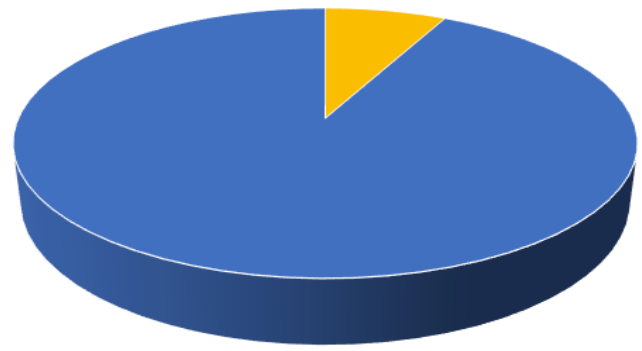

$-1=2-3=4 \cdot 5$

Item 8 clearly established one fact: Learners prefer the conventional classroom for Grammar exercises. Eighty percent $(\mathrm{N}=32)$ reported this preference over CALL. This was also seen by the researcher in conventional EFL classes as the respondents showed unusual enthusiasm tackling Grammar items collaboratively using the brainstorming technique. Representing this graphically:

8. My English Grammar skills improve the most when we brainstorm to answer simple exercises in the class.



The researcher had observed that Literature items were the most challenging to deal with using the conventional methods. However, every time a YouTube show was planned to teach Drama or any other Literature item in the CALL sessions, learner excitement was perceptible to everyone. This also shows in the responses with $90 \%$ (N=36) responding positively to the use of Multimedia for literature content.

\section{Use of Multimedia improves my language experience} when the teacher uses it for the Literature sections.

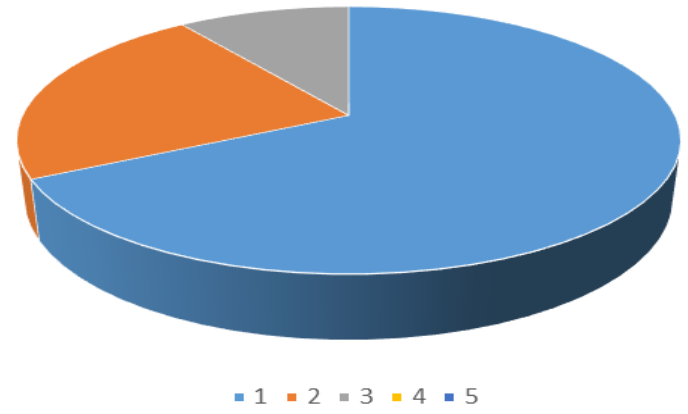

Contrary to expectations, CALL sessions were not found to be useful by a majority of $77.5 \%$ ( $N=31$ ) for listeningspeaking activities. This was also corroborated by classroom observation by the researcher who found the learners more actively engaged in the same during conventional teaching sessions. 
10. The interactive exercises for Listening-Speaking give me real life language use opportunities.



\section{Conclusion and Recommendations}

Computers have today become inseparable from language teaching-Learning. However, impact and effectiveness are two different things. Whereas impact can be quantified by measuring the extent of ICT in EFL, availability of related facilities both in terms of software and hardware, measuring the perceptions of the teacher-learner combine, budget allocations and many other parameters, effectiveness measures how CALL is better as a teaching tool than conventional methods used in the language classroom. This study had aimed at measuring this factor and has happily been able to arrive at some pertinent conclusions as seen in the previous section. Now for some recommendations:

1. Computers should certainly not be taken as the perfect replacement for teachers. At best, we can aim for Blended Learning where the teacher and technology work in tandem for learners' benefit.

2. Shifting the language learning paradigm entirely to options such as CALL will not address the needs of the Saudi EFL learner.

3. There is a need to study how teachers may be trained to better use technology in their language classrooms.

4. Language learning is not only about correctness but also appropriateness. It needs be evaluated how far CALL can supplement language lessons with this essential input which was so far the sole territory of the language teacher.

5. Focus needs be shifted to what teachers can do with language programmes rather than what these programmes can do on their own in the language classroom.

6. Programmes and materials specific to the needs of the Arab EFL learners and teachers need to be developed.

\section{References}

Allwright, D. (1983). Classroom Centered Research on Language Teaching and Learning: A Brief Historical Overview TESOL Quarterly, 17(2), 191-204

Beasley, R. and Riordan, L. (1981). The classroom teacher as researcher. English in Australia, 55, 36-41.

Chapelle, Carol A. (2009). The Relationship between Second Language Acquisition Theory and Computer-Assisted Language Learning. The modern language journal, 93, 741-53.

Cohen, L., \& Manion, L. (1985). Research methods in education. London: Croom Helm.

Craig, Ch. (1988). Second Language Classrooms: Research on Teaching and Learning. Cambridge: Cambridge University Press.

Duff, P. A. (1995). An Ethnography of Communication in Immersion Classrooms in Hungary. TESOL Quarterly 29(3), 505-537.

Garrett, N. (2009). Computer-Assisted Language Learning Trends and Issues Revisited: Integrating Innovation. The Modern Language Journal, 93, 719-40.

Gu, X., Wang, H., and Mason, J. (2017). A Cross-Cultural Study on the Relationship of Thinking Styles and Emerging Roles in Computer-Supported Collaborative Learning. The modern language journal, 20(1), 13-24

Heift, T., and Anne, R. (2012). Task-Related Variation in Computer-Assisted Language Learning. The modern language journal, 96(4), 525-43.

Ho, Sh., Hsieh, Sh., Sun, P. and Chen, Ch. (2017). Listen and Speak in Real Life Context with an AR Featured ULearning System." System, 20(2),176-87.

Kuo, Y., Belland, B. R. and Kuo, .T. (2017). Students' Perspectives in Collaborative Blog-Enhanced Learning Communities. System, 20(2), 37-50.

Levy, M. (1997). CALL: Context and Conceptualisation. Oxford: Oxford University Press.

Mørch, Anders I., Engeness, I., Cheng, V. C., Cheung, W. K. and Wong, K. C. (2017). "Writing to Learn with a Knowledge-Based Design Critiquing. System. 20(2), 213-23.

Kemmis, Stephen; and McTaggart, Robin, eds. (1988). The action research planner, third edition. Victoria: Deakin University.

Nunan, D. (1989). Designing tasks for the communicative classroom. Cambridge: Cambridge University Press. 